\title{
The role of music in the development of children with Down Syndrome: a systematic review
}

\author{
Moreno-Garcia Gemma ${ }^{1}$, Monteagudo-Chiner Pablo², Cabedo-Mas
}

Alberto $^{3}$

${ }^{1}$ Universitat de València, València, Spain; ${ }^{2}$ Departament d'Educació Física i Esportiva, Universitat de València, València, Spain; ${ }^{3}$ Departament d'Educació i Didàctiques

Específiques, Universitat Jaume I, Castelló, Spain

\begin{abstract}
Music is commonly used in special education to achieve developmental and therapeutic aims, often in people with special needs. The present article conducts a systematic review of results from previous studies that explore the role of music in the development of children with Down Syndrome (DS). It analyzes a sample of 19 articles, in English and Spanish, from several databases (ERIC, Scopus, SciELO, Dialnet, Web of Science, Base del CSIC and Pubmed). The results show that music has positive effects in the treatment and progress of the four main areas of development (social-emotional, motor, cognitive and communication) in children with DS. Nevertheless, the review reveals a lack of detail in the methodologies used and in the specific development areas, which call for further clarification in future research. These aspects are discussed in order to gain more conclusive results from future studies.
\end{abstract}

Keywords: Music therapy, music education, special education, social development, language development, Down syndrome.

\section{Introduction}

In the last years, academic interest has grown in the effects of music on the human body as a therapeutic resource and in scientific experimentation to explore these effects (Porter et al. 2017a). Findings have shown that activities such as singing, active listening, instrument playing, corporal movement and composition of new music have 
played a major role in musical therapies (Schmidt Peters 2000).

Current evidence suggests that music education and music therapy has a medium to large effect on behavior and general development in individuals (Gold, Wigram, and Voracek 2007). According to Pitts (2007), taking part in music-related activities facilitates the development of personal relationships and increases children's confidence, and enhances their social life and their sense of group belonging. Similarly, language and music have been shown to use the same perceptive and cognitive procedures; for example, humming a simple, familiar melody activates complex auditory procedures, attention, memory and the circuits of sensorial integration of the brain (Zatorre 2005). The benefits linked to motor development are also well known; Schlaug, Norton, Overy, and Winner (2005) reported that learning to play an instrument can improve fine motor skills. Betancourt and Hernández's (2012) study of the effect of a music program on children's functional performance demonstrated that certain motor skills, such as galloping and jumping, improved during the program. Furthermore, at a cognitive level numerous studies confirm that active participation in musical activities has a direct impact on the growth of visual and spatial intelligence (Herholz and Zatorre 2012).

Accordingly, the effect of certain music education practices and music therapy on the development of individuals with special needs is well known and research shows that the use of music in the classroom with students with special needs can assist and enhance academic performance, behavior, and communication (Hammel and Hourigan 2017; Ichinose et al. 2016; Kim, Wigram, and Gold 2009; VanWeelden, HeathReynolds, and Leaman 2017). Music therapies have been observed to achieve specific goals in patients with neurological disorders (Canicio, Guardiola, and Moreno 2017; Raglio et al. 2015), Asperger syndrome (Lee 2014), emotional and behavioral problems 
(Porter et al. 2017b) and autism spectrum disorder (Foley 2017; Gold, Wigram, and Elefant 2006). However, studies into the effects of music on the development of children with Down syndrome (DS) have had a relatively lower impact when the number of people affected by this syndrome is taken into account. For example, between one and two babies are born with DS each day in the United States, which means that about one baby in 1000 has the condition (Guy and Neve 2005). DS is a developmental disorder resulting from the presence of an additional whole or part copy of chromosome 21, which disrupts many aspects of cognitive and sensory-motor development. There is therefore a clear need to explore the results of research that analyzes the benefits of music therapy in children with DS.

The aim of this study is to classify improvements resulting from music experiences in the areas of development of children with DS. As this is still an emerging field of research, the study focuses on the most commonly used musical methods and procedures for this population to identify potential areas for future research.

\section{Materials and Methods}

A systematic literature search was conducted from seven online literature databases, namely ERIC, Scopus, SciELO, Dialnet, Web of Science, CSIC and Pubmed, according to the guidelines of the Preferred Reporting Items for Systematic Reviews and Metaanalysis (PRISMA) protocol (Moher, Liberati, Tetzlaff, Altman, and Prisma Group 2009). In addition, we performed a manual search through Google Scholar using specific references found in the selected articles in order to detect any additional relevant literature.

The research intended to give response to the following question: What is the role of music in the development of children with DS? 
To this aim, we searched for research in the fields of music therapy, music education and special needs education. The search terms used were: Down syndrome, music, music therapy, effects and development; they were combined with the Boolean operators "AND" and "OR" to refine the search and to connect words with similar meanings. Due to the lack of a significant number of available recent studies in the area the search was extended to investigations undertaken during the last twenty years limiting the search to papers published since 2000, and focused exclusively on full papers written in either English or Spanish in the fields of education, arts and social science.

\section{Inclusion and Exclusion Criteria}

Having previously limited the results by publication date and field of study, all original papers in English and Spanish on the impact of music in the development of children with Down syndrome were deemed valid for consideration. Incomplete papers were then rejected and the abstract and methodology of the preselected studies were read to establish the following inclusion criteria: papers where music plays a significant role as a treatment therapy; scientific or specialized publications; studies including child participants. We excluded studies that failed to provide adequate demographic data about the participants, and others with a focus on adults. Bachelor dissertations and Master's theses were also excluded. Two reviewers (Author 1 and Author 2) independently reviewed all the titles and abstracts retrieved from the search according to specific predefined inclusion criteria. In the next stage of the search, the two reviewers discussed the eligibility of each article and reached a consensus on which ones to include. 


\section{Results}

Our search resulted in 195 articles, of which only 19 satisfied the criteria described above and were, thus, eligible for inclusion in this review. The initial automated search of the databases yielded 5 titles from Dialnet, 23 titles from ERIC, 62 from Web of Science, 67 from Scopus, 8 from CSIC, 3 from SciELO and 27 from Pubmed. After the first search, articles in more than one database and with partial content were excluded, leading to a total of 137 original studies as candidates for inclusion in the review. Subsequently, the full texts of the selected articles were carefully and critically evaluated according to the review inclusion criteria. This process led to the final selection of 15 studies that met our inclusion criteria. Furthermore, we searched all the reference lists from these 15 articles to detect any unidentified literature; this yielded 4 additional articles, raising the total number of potentially eligible manuscripts to 19 . These manuscripts came from the fields of music education and music therapy.

A flow diagram analytically describing the article selection process is presented in Figure 1.

\section{***Figure 1 NEAR HERE ***}

\section{Areas of child development}

All the selected studies were classified attending the area of child development covered in the music experiences, applications or therapies.

As shown in Figure 1, the 19 selected studies were clustered in the areas Motor development (5\%), Communication development (10\%), Social and Emotional 
development (37\%), Cognitive development (16\%) and; a Multi-area (32\%) section was also added for studies that deal with more than one area at the same time.

\section{General characteristics of studies}

The general characteristics of the 19 studies are summarized in Table 2.

Eleven studies were published after 2010. Eight studies were published from 2002 to 2009. Seven originated from Europe, ten from the U.S., one from Asia and one from New Zealand. Regarding the seven articles from Europe, four reported findings from heterogeneous samples of patients: DS, cerebral palsy, mental delay and autism, among others. Similarly, articles from the U.S. reported outcomes derived from different groups of participants: DS, Williams syndrome, Prader-Willi syndrome, autism and cerebral palsy. In ten articles, the sample comprised exclusively Down syndrome patients; in seven papers, the sample included patients with multiple mental and motor disorders; and in two studies a group with DS was compared with a group with no disorder. Five of the articles focused on patients and their family context and two articles were a review of previous studies. Only ten studies specified the patient's gender and thirteen papers stated participants' age range; exact ages were provided in eight studies.

***Table 2 NEAR HERE ***

Regarding the metrics of the studies, $66 \%$ of the articles were indexed in Journal Citation Reports (JCR) or Scimago Journal Rank (SJR). From this 66\%, six articles had an impact factor over 1.5, and five articles had the impact factor between 0.1 and 1.5. 


\section{Motor development area}

Positive but limited results have been reported for psychomotor development. Camps, Prina and Rodríguez (2017) conducted a quasi-experimental study of two groups of four children with Down syndrome in which music was used together with psychomotor sessions in the experimental group as a tool for improving manual dynamic coordination, general dynamic coordination, balance, spatial organization and adaptation to rhythm. However, significant differences were only found in manual coordination and adaptation to rhythm in the experimental group. Guy and Neve (2005) also suggested that music therapy can help to improve fine motor skills with instrument exercises such as beating a drum. In a case-study in a music education experience conducted by Becker and Dusing (2010) the participant took part in a 14-week performing arts program that included instruction in dance (jazz and ballet), voice, and acting. By the end of the program the participant was able to run with improved coordination, increased speed, decreased loss of balance, and a narrower base of support. Finally, the parents of children with DS interviewed in the study by Pineda and Pérez (2011) perceived their children improved in motor skills after music therapy based on corporal expression games and activities. However, the procedures used to evaluate these skills during the study are not detailed.

\section{Communication development area}

Attending to the area of communication, a qualitative investigation into the effects of music in the communication skills of children with Down syndrome was conducted by Pienaar (2012), who examined the perspectives of 19 caregivers of children with DS working in a special school environment. An anonymous questionnaire completed by 
the participants showed positive effects of music therapy sessions. Caregivers confirmed that conversation was possible through a music therapy session; children recognized songs and lyrics, were keen to play instruments, and repeated sounds, thus facilitating more effective communication than in other classroom situations. They found that music has the potential to enhance the communication development of children with DS. In addition, in their study on the impact of playing the wadaiko (traditional Japanese drum) on people with mental disabilities Mizuno and Sakuma (2013) reported that players communicated through rhythm, gestures and eye contact. Through playing this instrument, the participants, one of whom was a child, improved their ability to communicate.

Guy and Neve (2005) reported on communicative skills in music therapy activities with people with DS. They found that music therapy contributes to the development of speech and language skills, helps to target oral motor skills and can even develop orbicular muscles using simple musical instruments such as the slide whistle. These authors stated that co-treatment with a speech therapist enhances the effectiveness of music therapy. Supporting these ideas, in their descriptive study from the perspective of the parents and teachers of children with DS following a 9-month music therapy program Pineda and Pérez (2011) confirmed that children with DS showed improved communicative skills, more extensive vocabulary and enhanced pronunciation of phonemes. Moreover, in the experimental program conducted by Vitoria-Gallastegi (2005a) relating to music education and students with special needs, musical experience was associated with an improvement in psycholinguistic skills such as comprehension, auditory association, verbal expression and verbal memory in children with disabilities, with the greatest results among children with DS. 


\section{Social-emotional development area}

Although Rosner, Hodapp, Fidler, Sagun and Dykens (2004) showed that the participants with DS in their study preferred to perform musical activities and had higher overall social competence scores than those with Prader-Willi and Williams syndromes, some difficulties seem to be found with regard to the social and emotional development of children with DS.

In the area of social-emotional development, almost every study in this review found positive effects of music among children with DS in their relationships and selfimage, as Polo-Dowmat (2002) stated in her article. Guy and Neve (2005) also noted that musical experience helps such children acquire positive self-image, feel more productive, and engage more with society.

In their experimental study, Gómez-Scarpetta et al. (2012) evaluated dental anxiety among 30 children with DS using music therapy during consultation. Their results showed a significant decrease in anxiety levels following the therapy. Camps, Prina and Rodríguez (2017) also reported that music calmed patients' anxiety and caused improvements in their breathing and relaxation. Pienaar (2012) suggested that group music therapy can benefit children with DS since it motivates them to interact socially in an emotionally safe environment.

In the field of music education, Morgante's (2014) research on social integration of people with special needs described how music helped raise levels of trust and calmness, thus enabling interaction between students with disabilities and their classmates. Arguedas-Quesada (2015), citing Lagos (2004) and Gutiérrez et al. (2012), described how music helps participants to feel relaxed, empathize with classmates, control emotions, and participate more fully in daily life. Thus, music contributed to social development by improving people's quality of life. Bell (2008) found that the 
student in his study was able to communicate feelings and thoughts that he could not express through conversation.

In turn, Becker and Dusing's (2010) study confirmed that, according to one participant's mother, music lowered the girl's anxiety, and increased her self-confidence and peer interaction, thus improving her quality of life. Mizuno and Sakuma (2013) found that playing instruments helped to raise the self-confidence of performers with DS, and allowed them to establish relationships with others, thus enabling them to adjust to social life.

Pineda and Pérez (2011) and Theodorou and Drigas (2017) affirmed that music increased children's participation in social activities and promoted the acquisition of values and understanding of rules.

Finally, Heaton, Williams, Cummins and Happé (2008) analyzed how social deficit curtails musical understanding in individuals with autism and DS; they suggested that emotion-processing deficits in children with DS are not directly related to musical ability, concluding that musical understanding is in fact related to the level of communication development.

\section{Cognitive development area}

Overall, most of the studies provided limited evidence for the use of music in the cognitive development of DS children. On the one hand, Virji-Babul et al. (2013), compared brain activation in individuals with DS when listening to familiar and unfamiliar melodies (composed in the same key and played with the same musical instrument). Three areas showed significant activation: the left primary auditory region, the left superior temporal sulcus and the right premotor region. These authors suggested that familiar music is associated with auditory-motor coupling but it does not activate 
brain areas involved in emotional processing in people with DS. On the other hand, L'Etoile (2015) reported that mothers' directed singing to children with DS for a period of two minutes contributed to maintaining attention evaluated with the Infant Behavior Rating Scales-Revised (IBRS-R), specifically for changes in the direction of the gaze and the affect component of the subjects during the singing activity. Finally, Jiménez et al. (2011) outlined a proposal for music intervention to stimulate visual and auditory short-term memory. This proposal is based on the repetition of short rhythmic stimuli with a drum and with the so-called "rainbow piano". According to these authors, the intervention stimulated three cerebral areas with poor functioning in this syndrome: the hippocampus, the prefrontal lobe and the cerebellum.

\section{Discussion}

The studies reviewed show preliminary evidence of possible benefits of music and music therapy in patients with DS. Coinciding with Wigram et al. (2002), the studies analyzed reinforce the idea that children with DS seem to respond specifically to music, and show potential to participate in group music making. However, although there is a positive tendency highlighting the benefits of using music with people with DS, the review reveals some interesting limitations that need to be addressed.

The review shows a lack of systematic measures in music therapy treatments to improve motor skills development in individuals with DS. Although the studies provide general advice on what may be beneficial (Guy and Neve 2005), we did not find evidence of a series of musical interventions that systematically measured improvements. While Becker and Dusing (2010) reported preliminary evidence of increased motor abilities, the case-study research did not describe the specific motor changes resulting from the intervention. The research shows the potential of 
community-based performing arts programs in the social, physical and psychological development of people with DS, but further studies on specific music therapy interventions are needed to identify the benefits music has for the development of particular motor skills. Furthermore, while Camps, Prina and Rodríguez (2017) studied psychomotor abilities (manual dynamic coordination, general dynamic coordination, balance, spatial organization and adaptation to rhythm), they examined the influence of music in interventions expressly designed to develop motor skills. In this sense, their research could not specifically evaluate the benefits of active music making in motor development. On the other hand, the same authors point out that music has a motivating role, coinciding with other works that discuss the mediating role that music can play as a support to complement physical exercise (Ramos and Zamorano 2003). These findings suggest that in tasks designed to improve motor development, the quality of movement is more important than the type of music used. In conclusion, we believe there is a need to conduct further systematic interventions that analyze the effects of music therapy programs, through the active response to music, body expression and/or dance therapy, in motor development.

The use of music in developing communication skills has been widely studied (see, for example, Chan, Ho and Cheung 1998). Music therapy has been used to improve communication abilities, especially in patients with disorders that directly affect communicative abilities, such as autism (Gattino, Riesgo, Longo, Leite, and Faccini 2011; Kim et al. 2009; Perry 2003). Research into the use of music to develop communication skills in people with DS is more limited, however. Previous research has demonstrated that children with DS show no differences in responding and echoing musical and alphabetical series (Bokor, 1976), indicating that the syndrome does not specifically limit musical responses, in comparison to verbal responses. Taking this 
finding into consideration, some studies have suggested that musical training may be a positive way of improving verbal communication. Pienaar (2012) confirmed this hypothesis through her analysis of the perceptions of caregivers and music therapists. Similarly, Pineda and Pérez (2011) analyzed perceptions of parents and teachers in an intervention using music with patients with DS, describing improvements in language development. Most of the studies that analyzed communication development used qualitative research methods, mainly interviews with indirect participants (families, caregivers, teachers, therapists), as the basis for the results. Vitoria-Gallastegi's (2005a) study was the only one we found that used a standardized test (Illinois Test of Psycholinguistic Abilities) to measure results. Although we recognize the potential benefits of using mixed methods to detect analyze and understand results, we believe there is a need for more systematic quantitative research to explore the influence and effects of music making in individuals with DS. Furthermore, the design and implementation of randomized controlled studies may provide interesting information in relation to this fascinating line of research. Similar conclusions arise when exploring the effects of music in the area of cognitive development.

The largest volume of research in our review concerned the area of social and emotional development. Research using music with people with DS has often explored parameters such as anxiety (Becker and Dusing 2010; Gómez Scarpetta et al. 2012), social integration (Morgante 2014; Pineda Pérez and Pérez Remón 2011; Theodorou and Drigas 2017) or self-confidence (Mizuno 2013). Every study in this review reported positive outcomes of active participation in music making. These findings highlight the potential benefits music has in the emotional areas and in the development of social skills. Most of the studies included in the social and emotional dimension used qualitative methods to describe the intervention outcomes. Quantitative studies included 
in the review (Gómez Scarpetta et al. 2012; Rosner et al. 2004) were descriptive and did not use musical interventions aimed at developing social or emotional skills. Some of the studies included (Arguedas-Quesada 2015; Morgante 2014) belong to the field of music education and/or community music and, although they report on particular benefits in the field of socioemotional development, they are not specifically designed to use music therapeutically. Some of the studies (Becker and Dusing 2010; Gómez Scarpetta et al. 2012) provided very precise definitions of the dimension of the socioemotional development studied. Other studies took a more holistic view of socioemotional development, addressing concepts such as social integration (Morgante 2014) or human development (Arguedas-Quesada 2015), which do not include a psychological construct with specific dimensions that can be measured with standardized research instruments (test, questionnaires, scales, etc.). In light of the review, although we acknowledge the importance of reflecting on the benefits of music from a holistic point of view, we highlight the need for research on the impact of music therapy in specific psychological constructs that delimit what is included in the social and the emotional development studied.

Finally, the term music therapy has used to describe the collective literature reviewed, but it is important that future studies differentiate between music interventions that require delivery from a credentialed music therapist and those that can be delivered by other professionals like a complement in their field (for example in physical education) (Robb et al. 2018).

\section{Conclusions}

This review highlights the importance of designing further research using music activity with people with DS. To this end, significant aspects need to be taken into account. The review reveals a need for studies that, beyond exploring the general and 
holistic benefits of music in overall development, isolate the variables studied to determine the possible effects of musical interventions. We consider that designing randomized controlled studies including people with DS may help to advance knowledge in this field of research.

The studies analyzed used mainly qualitative research methods, and we found a scarcity of systematic experimental studies, using quantitative or mixed methods, that allow meta-analysis to be conducted.

This review describes preliminary evidence on the multiple benefits active music making may have for the motor, communicative, socioemotional and cognitive development of people with DS. Other systematic reviews (Brown and Jellison 2012; Weller and Baker 2011) have analyze the effects of music therapy in other fields of research, contributing valuable information about the impact of music therapy treatments. However, there are areas of music therapy for people with DS that remain unexplored. The review has limited the fields of study and articles from other areas that have been excluded (like Neurosciences) may have contributed to a more holistic view of the object of study. Also the effect of different kind of music, tonalities, instruments, volume and properties of sounds could be investigated in this population.

Although DS presents unresolved challenges, this underexplored field of research seems promising. We hope that this review will provide a platform for stimulating advances as well as a rationale for immediate improvements in music therapy interventions for people with DS.

\section{References:}

Arguedas-Quesada, C. 2015. "Educación musical, desarrollo infantil y adolescente y enfoque de derechos humanos: Una reseña bibliográfica”. Revista de Educación, 39(2), 79-103. Retrieved from https://doaj.org/article/aa72be8774524215bb26d370c21fac0f 
Becker, E., and Dusing, S. 2010. "Participation is possible: A case report of integration into a community performing arts program”. Physiotherapy Theory and Practice, 26(4), 275-280. doi:10.3109/09593980903423137

Bell, A. P. 2008. "The heart of the matter: Composing music with an adolescent with special needs". International Journal of Education and the Arts. Retrieved from https://eric.ed.gov/?q=down+syndrome+musicandid=EJ800906

Bello, M. A. R. 2007. “Incidencia y prevalencia del síndrome de Down”. Revista De Sindrome De Down, 24, 2-4.

Betancourt, J. E., and Hernandez, M. 2012. "The effect of physical and music education in the development of motor skills in children between six and eight year-olds in an inclusive environment”. NALS Journal, 4(1), 1.

Bokor, C. R. 1976. “A comparison of musical and verbal responses of mentally retarded children". Journal of Music Therapy, 13(2), 101-108.

Bonde, L. O., and Wigram, T. 2002. A comprehensive guide to music therapy: Theory, clinical practice, research and training. London. Jessica Kingsley Publishers.

Brown, L. S., and Jellison, J. A. 2012. "Music research with children and youth with disabilities and typically developing peers: A systematic review”. Journal of Music Therapy, 49(3), 335-364.

Camps, A., Prina, S., and Rodríguez, J. Á. 2017. "Beneficios de la música en la práctica psicomotriz del niño con síndrome de Down”. Rey Desnudo: Revista de Libros, 5(10), 1-2. Retrieved from https://doaj.org/article/8ca90872f4024163afcd0013d16f23cb

Canicio, D. A., Guardiola, A., and Moreno, M. 2017. "Revisión bibliográfica: Beneficios de la musicoterapia en personas con enfermedad de Alzheimer”. Terapia Ocupacional, 1(1).

De l'Etoile, S. K. 2015. "Self-regulation and infant-directed singing in infants with Down syndrome”. Journal of Music Therapy, 52(2), 195-220. doi:10.1093/jmt/thv003 [doi]

Foley, S. V. 2017. "The benefits of music education on academic, behavioral, and communicative skills with middle school students with autism spectrum disorder". Master's Theses and Capstone Projects. 266. https://scholar.dominican.edu/masters-theses/266

Gattino, G. S., Riesgo, R. d. S., Longo, D., Leite, J. C. L., and Faccini, L. S. 2011. "Effects of relational music therapy on communication of children with autism: 
A randomized controlled study". Nordic Journal of Music Therapy, 20(2), 142154.

Gold, C., Wigram, T., and Elefant, C. 2006. "Music therapy for autistic spectrum disorder". Cochrane Database of Systematic Reviews, 2.

Gold, C., Wigram, T., and Voracek, M. 2007. "Effectiveness of music therapy for children and adolescents with psychopathology: A quasi-experimental study". Psychotherapy research, 17(3), 289-296.

Gómez-Scarpetta, R. Á, Durán-Arismendy, L., Cabra-Sosa, L. J., Pinzón-Vargas, C. T., and Rodríguez-Becerra, N. R. 2012. "Musicoterapia para el control de ansiedad odontológica en niños con Síndrome de Down”. Revista hacia la promoción de la salud, 17(2).

Gutiérrez, P., Ibáñez, P., and Prieto, S. 2012. "Yo quiero ser Marifé de Triana. experiencia para el desarrollo de la inteligencia emocional a través de la musicoterapia". Tejuelo: Didáctica de la Lengua y la Literatura. Educación, (13), 24-46.

Guy, J., and Neve, A. 2005. "Music therapy and Down syndrome fact sheet". Meloteca, l(1).

Hammel, A. M., and Hourigan, R. M. 2017. Teaching music to students with special needs: A label-free approach. Oxford: Oxford University Press.

Heaton, P. 2008. "Do social and cognitive deficits curtail musical understanding? Evidence from autism and Down syndrome". British Journal of Developmental Psychology, 26(2), 171-182.

Herholz, S. C., and Zatorre, R. J. 2012. "Musical training as a framework for brain plasticity: Behavior, function, and structure". Neuron, 76(3), 486-502.

Ichinose, T., Takehara, N., Matsumoto, K., Aoki, T., Yoshizato, T., Okuno, R., Akazawa, K. 2016. "Development of a system combining a new musical instrument and kinect: Application to music therapy for children with autism spectrum disorders". International Journal of Technology and Design Education, 938-947.

Jiménez, M. R., Risco, M. L., Jiménez, R. P. R., Jiménez, J. C. R., and Gómez, A. G. 2011. "Síndrome de Down: Propuesta de un programa de intervención cognitiva en memoria a corto plazo a través de la música". International Journal of Developmental and Educational Psychology, 1(4), 523-532. 
Kim, J., Wigram, T., and Gold, C. 2009. "Emotional, motivational and interpersonal responsiveness of children with autism in improvisational music therapy". Autism, 13(4), 389-409.

Lagos, E. 2004. "Musicoterapia en niños con síndrome de Down: La importancia del vínculo en la creatividad y desarrollo emocional”. Universidad De Chile. http://Www.Tesis.Uchile.Cl/Tesis/Uchile/2004/Lagos_e/Htm1/IndexFrames.Html,

Lee, L. 2014. "The effect of music activities in a multi-sensory room for children with Asperger's syndrome on behavioral changes: A case study". ISME Commission on Music in Special Education, Music Therapy, and Music Medicine, 31.

López, G., Marfil, G., Jiménez, G., Escamilla, G., and Gómez, M. 2014. “Síndrome de Down”. Breve Estudio Epidemiológico De Morbiletalidad, 25, 8-12.

Mizuno, E. 2013. "Performance enhances synchronized motion of mentally disabled persons". Perceptual and Motor Skills, 116(1), 187-196.

Moher, D., Liberati, A., Tetzlaff, J., Altman, D. G., and Prisma Group. 2009. "Preferred reporting items for systematic reviews and meta-analyses: The PRISMA statement”. PLOS Medicine, 6(7), e1000097.

Moreno, J. L. 1990. Musicoterapia en educación especial. Madrid: Editum.

Morgante, B. 2014. "La pedagogía musical como integrador social para la discapacidad". Pensamiento, Palabra y Obra, 11(11), 78-86. Retrieved from https://dialnet.unirioja.es/servlet/articulo?codigo=5271203

Pérez Chávez, D. A. 2014. "Síndrome de Down”. Revista De Actualización Clínica Investiga, 45, 2357.

Perry, M. M. R. 2003. "Relating improvisational music therapy with severely and multiply disabled children to communication development". Journal of Music Therapy, 40(3), 227-246.

Pienaar, D. 2012. "Music therapy for children with Down syndrome: Perceptions of caregivers in a special school setting". Kairaranga, 13(1), 36-43. Retrieved from https://eric.ed.gov/?q=down+syndrome+music\&id=EJ976663

Pineda, E., and Pérez, Y. 2011. "Musicoterapia aplicada a niños con síndrome de Down”. Revista Cubana De Pediatría, 83(2), 142-148.

Pitts, S. E. 2007. “Anything goes: A case study of extra-curricular musical participation in an English secondary school”. Music Education Research, 9(1), 145-165. 
Polo-Dowmat, L. 2002. "Yo puedo, tú puedes... la expresión artística como puente de comunicación para personas con discapacidad". Arte, Individuo y Sociedad; 2002: Anejo I; 405 - 409, , 405-409. Retrieved from http://revistas.ucm.es/index.php/ARIS/article/view/ARIS0202110405A

Porter, S., McConnell, T., McLaughlin, K., Lynn, F., Cardwell, C., Braiden, H., Boylan, J., Holmes, V. 2017. "Music therapy for children and adolescents with behavioural and emotional problems: A randomised controlled trial". Journal of Child Psychology Psychiatry, 58(5), 586-594.

Raglio, A., Attardo, L., Gontero, G., Rollino, S., Groppo, E., and Granieri, E. 2015. "Effects of music and music therapy on mood in neurological patients". World Journal of Psychiatry, 5(1), 68.

Ramos, B. L., and Zamorano, M. Á S. 2003. "La música como recurso didáctico en educación física". Retos: Nuevas Tendencias En Educación Física, Deporte Y Recreación, (6).

Robb, S. L., Hanson-Abromeit, D., May, L., Hernandez-Ruiz, E., Allison, M., Beloat, A., ... \& Polasik, S. (2018). Reporting quality of music intervention research in healthcare: A systematic review. Complementary therapies in medicine, 38, 2441.

Rosner, B. A., Hodapp, R. M., Fidler, D. J., Sagun, J. N., and Dykens, E. M. 2004. "Social competence in persons with Prader-Willi, Williams and Down's syndromes". Journal of Applied Research in Intellectual Disabilities, 17(3), 209-217.

Schlaug, G., Norton, A., Overy, K., and Winner, E. 2005. "Effects of music training on the child's brain and cognitive development". Annals of the New York Academy of Sciences, 1060(1), 219-230.

Schmidt Peters, J. 2000. Music therapy: An introduction (2nd ed.), Springfield, Charles C Thomas.

Theodorou, P., and Drigas, A. 2017. "ICTs and music in generic learning disabilities". International Journal of Emerging Technologies in Learning, 12(04), 101-110.

VanWeelden, K., Heath-Reynolds, J., and Leaman, S. 2017. "The effect of a peer mentorship program on perceptions of success in choral ensembles: Pairing students with and without disabilities". Applications of Research in Music Education, 36(1), 37-43. 
Virji-Babul, N., Moiseev, A., Sun, W., Feng, T., Moiseeva, N., Watt, K. J., and Huotilainen, M. 2013. "Neural correlates of music recognition in Down syndrome". Brain Cognition, 81(2), 256-262. doi:10.1016/j.bandc.2012.11.007

Vitoria-Gallastegi, J. R. 2005a. "Educación musical y desarrollo psicolingüístico de personas con necesidades educativas especiales". Revista de Psicodidactica, 10(2), 17-26. Retrieved from http://www.ehu.es/ojs/index.php/psicodidactica/article/view/187/183

Vitoria-Gallastegi, J. R. 2005b. "Enseñanza musical y aprendizaje instrumental en personas con síndrome de Down, parálisis cerebral, retraso mental y autismo". Paper presented at the V Congreso Internacional Virtual De Educacion. Universitat de les Illes Balears.

Weller, C. M., and Baker, F. A. 2011. "The role of music therapy in physical rehabilitation: A systematic literature review". Nordic Journal of Music Therapy, 20(1), 43-61.

Zatorre, R. 2005. “Music, the food of neuroscience?” Nature, 434(7031), 312. 